Article

\title{
Improving In-Situ Estimation of Soil Profile Properties Using a Multi-Sensor Probe
}

\author{
Xiaoshuai Pei ${ }^{1}$, Kenneth A. Sudduth ${ }^{2, *}$, Kristen S. Veum ${ }^{2} \mathbb{D}$ and Minzan Li ${ }^{1}$ \\ 1 Key Laboratory of Modern Precision Agriculture System Integration Research-Ministry of Education, \\ China Agricultural University, Beijing 100083, China; xiaoshuaipei@163.com (X.P.); limz@cau.edu.cn (M.L.) \\ 2 USDA-ARS Cropping Systems and Water Quality Research Unit, Columbia, MO 65211, USA; \\ Kristen.Veum@ars.usda.gov \\ * Correspondence: Ken.Sudduth@ars.usda.gov
}

Received: 13 December 2018; Accepted: 22 February 2019; Published: 27 February 2019

\begin{abstract}
Optical diffuse reflectance spectroscopy (DRS) has been used for estimating soil physical and chemical properties in the laboratory. In-situ DRS measurements offer the potential for rapid, reliable, non-destructive, and low cost measurement of soil properties in the field. In this study, conducted on two central Missouri fields in 2016, a commercial soil profile instrument, the Veris P4000, acquired visible and near-infrared (VNIR) spectra (343-2222 nm), apparent electrical conductivity $\left(\mathrm{EC}_{\mathrm{a}}\right)$, cone index $(\mathrm{CI})$ penetrometer readings, and depth data, simultaneously to a $1 \mathrm{~m}$ depth using a vertical probe. Simultaneously, soil core samples were obtained and soil properties were measured in the laboratory. Soil properties were estimated using VNIR spectra alone and in combination with depth, $\mathrm{EC}_{\mathrm{a}}$, and CI (DECS). Estimated soil properties included soil organic carbon (SOC), total nitrogen (TN), moisture, soil texture (clay, silt, and sand), cation exchange capacity (CEC), calcium $(\mathrm{Ca})$, magnesium $(\mathrm{Mg})$, potassium $(\mathrm{K})$, and $\mathrm{pH}$. Multiple preprocessing techniques and calibration methods were applied to the spectral data and evaluated. Calibration methods included partial least squares regression (PLSR), neural networks, regression trees, and random forests. For most soil properties, the best model performance was obtained with the combination of preprocessing with a Gaussian smoothing filter and analysis by PLSR. In addition, DECS improved estimation of silt, sand, CEC, Ca, and Mg over VNIR spectra alone; however, the improvement was more than 5\% only for Ca. Finally, differences in estimation accuracy were observed between the two fields despite them having similar soils, with one field demonstrating better results for all soil properties except silt. Overall, this study demonstrates the potential for in-situ estimation of profile soil properties using a multi-sensor approach, and provides suggestions regarding the best combination of sensors, preprocessing, and modeling techniques for in-situ estimation of profile soil properties.
\end{abstract}

Keywords: diffuse reflectance spectroscopy; precision agriculture; profile soil properties; proximal soil sensing; in-situ sensing

\section{Introduction}

Traditional agriculture applies uniform management to fields without considering the spatial heterogeneity of soil properties and plant growth. This contributes to potential over-application of chemical inputs such as fertilizer, pesticides, and herbicides, leading to increased environmental risk. In contrast, precision agriculture aims to manage at the field scale and apply inputs according to the needs of each area within a field. Thus, precision agriculture has the potential to improve crop production, prevent excess application of chemical inputs, reduce expenses, and reduce environmental impacts. To reach this goal, site-specific soil properties that affect plant growth and crop production need to be measured to provide a basis for precision agriculture management. Measuring multiple 
soil properties at a high temporal and/or spatial frequency is time consuming and costly, using conventional methods. Therefore, alternative approaches are needed to achieve high resolution, field scale information for producers.

Diffuse reflectance spectroscopy (DRS) is a promising, fast, nondestructive soil sensing technique that does not require laboratory soil analysis other than for development of calibration equations [1]. Many research projects have estimated soil physical and chemical properties using DRS in the visible (400 to $700 \mathrm{~nm}$ ), near-infrared (NIR; 700-2500 nm), or combined VNIR wavelength ranges [2]. With acceptable accuracy, diffuse reflectance spectroscopy could replace standard laboratory measurement methods at a reasonable cost in some cases. Furthermore, in-situ DRS measurements can provide an additional level of efficiency by removing the need to collect soil and transport it to the laboratory. In-situ DRS instruments can provide results immediately if suitable calibrations have already been developed and successfully applied in field settings [3-5]. Many soil properties have been successfully estimated using DRS. For example, total carbon has been estimated with $\mathrm{R}^{2}$ ranging from 0.73 to 0.95 [3,6-9]. Similarly, many studies have successfully estimated soil organic carbon (SOC), cation exchange capacity (CEC), calcium $(\mathrm{Ca})$, potassium $(\mathrm{K})$, texture (clay, silt and sand fractions), magnesium $(\mathrm{Mg}), \mathrm{pH}$, and other soil properties with DRS [6,10-15].

Studies estimating soil properties using DRS, including those described above, have primarily focused on surface soils, typically in the top $5-30 \mathrm{~cm}$ of the profile. In general, agricultural management and associated soil measurements focus on this surface layer that represents the interface between the soil and the atmosphere and is critical in plant growth and development. However, soil properties deeper in the profile are controlling factors for many aspects of soil function, including carbon storage and nutrient cycling (e.g., [16,17]). Therefore, profile DRS data and other profile soil information are potentially useful for agricultural management. Previous laboratory studies have demonstrated successful estimation of profile soil properties with DRS. For example, Dalal and Henry [18] estimated profile SOC, total nitrogen (TN), and soil moisture with $\mathrm{R}^{2}>0.84$. Others used NIR DRS to estimate profile moisture $\left(R^{2}=0.87\right)$ and SOC $\left(R^{2}>0.77\right)$ in the laboratory [19], and to estimate several profile soil properties, including clay, Ca, CEC, and SOC with $R^{2} \geq 0.80$ [20]. Another approach has been in-field spectrometry on intact, extracted soil cores [4], which was reported to successfully predict SOC at depth resolutions of up to $1 \mathrm{~cm}[21,22]$.

Acquisition of in-situ, profile soil information has been investigated by several groups, as it offers many potential benefits over laboratory DRS analysis of profile samples in terms of efficiency, timeliness, and expense. A penetrometer foreoptic developed for a prototype NIR spectrophotometer estimated soil moisture with $R^{2}=0.90$ [23]. In field studies, prototype penetrometer foreoptics coupled to commercial spectrometers estimated clay content with 20-25\% greater error compared to laboratory spectra on dried and sieved samples [24,25]. A commercial penetrometer instrument, the Veris P4000 (Veris Technologies, Salina, Kansas, USA) can be deployed in the field for profile VNIR DRS data collection. Data from this instrument has been used to estimate multiple soil properties. In one study, the cross-validation $\mathrm{R}^{2}$ of bulk density (BD), SOC, moisture, clay, silt, and sand were found to be $0.32,0.67,0.40,0.65,0.61$, and 0.38 , respectively [26]. In another study, texture and soil organic matter (SOM) were estimated with errors of $\sim 6 \%$ for clay and silt, 10 to $11 \%$ for sand, and 0.3 to $0.5 \%$ for SOM [27]. Soil organic carbon estimates from in-situ Veris $P 4000$ data were less accurate $\left(R^{2}\right.$ from 0.78 to 0.90$)$ than estimates from $P 4000$ data obtained in the laboratory on dry soil samples $\left(R^{2}\right.$ from 0.93 to 0.96 ) [28]. Veum et al. [29] reported similar results, with the root mean square error (RMSE) of prediction smaller $(0.19 \%)$ for SOC estimates based on laboratory DRS than for estimates based on in-situ DRS (0.26\%).

Soil property estimation with VNIR DRS requires the application of a multivariate calibration algorithm, often after the spectral data have been subjected to one or more types of mathematical pretreatment. No general consensus on the best spectral pretreatments has emerged in the literature [1]; rather the need to examine multiple pretreatments and combinations in a "trial-and-error" approach has been reported, both for different datasets and for different soil properties within the same 
dataset [30]. In some studies, little difference in calibration results has been reported across a range of pretreatments [31], but that is not always the case. Likewise, no single calibration algorithm has consistently provided the best results. In some cases, neural networks and machine learning algorithms have been reported as better than the more commonly used partial least squares regression (PLSR) [32]. In other studies, machine learning algorithms and PLSR have provided similar results [31,33]. Most evaluations of pretreatments and calibration algorithms have been done using laboratory DRS-few studies have done this evaluation for in-situ DRS. Thus, there is a need for further investigation of pretreatments and calibration algorithms applied to in-situ sensing.

Many studies have illustrated that VNIR spectra are sensitive to variable environmental conditions in the field, such as changes in soil structure, temperature, and moisture [11,34-36]. Specifically, $\mathrm{OH}$ bands from soil moisture are known to mask important spectral features produced by SOC and other soil properties [3], meaning that lab-based results on dry soil are often more accurate than in-situ results with field-moist soil. Thus, successful in-situ or in-field, profile estimation of soil properties often requires balancing a reduction in accuracy compared to laboratory analysis with improvements in operational efficiencies. One option for improving these measurements may be to combine data from auxiliary sensors with VNIR DRS data. For example, an in-field core-scanning system that included gamma-ray attenuation and digital imaging along with VNIR DRS was used to estimate multiple soil profile properties [37]. The Veris P4000 can measure apparent soil electrical conductivity $\left(\mathrm{EC}_{\mathrm{a}}\right)$, and penetrometer cone index $(\mathrm{CI})$, along with the depth of measurement. Adding these data to the calibration has been investigated for their potential to improve the estimation of the physical and chemical properties of soil profile $[26,27]$. Soil $\mathrm{EC}_{\mathrm{a}}$ reflects numerous soil physical and chemical attributes such as texture, mineralogy, CEC, and moisture [38-40]. Cone index, defined as the force per unit base area required to push a penetrometer through a specified increment of soil [41,42], is affected by soil compaction, soil bulk density, texture, and moisture [43-45].

The primary objective of this study was to estimate multiple soil profile properties using in-situ sensor data obtained using the Veris P4000 instrument: VNIR reflectance, $\mathrm{EC}_{\mathrm{a}}, \mathrm{CI}$, and depth. The target soil properties included SOC, TN, soil moisture, soil texture (clay, silt, and sand), CEC, $\mathrm{Ca}, \mathrm{Mg}, \mathrm{K}$, and $\mathrm{pH}$. The specific objectives were to evaluate and compare estimation accuracy across multiple soil properties for:

- Ten different spectral preprocessing techniques.

- Four calibration methods: PLSR, neural networks, regression trees, and random forests.

- All four sensors in combination compared to VNIR spectra alone.

- Single-field calibrations compared to those developed for multiple fields.

\section{Materials and Methods}

\subsection{Study Fields}

Sensor data and soil samples were obtained in March 2016 at Field 1 (F1, 36 ha) and Field 3 (F3, $20 \mathrm{ha}$ ), two long-term research sites [46] located within $3 \mathrm{~km}$ of each other, near Centralia $\left(39.230^{\circ} \mathrm{N}, 92.117^{\circ} \mathrm{W}\right)$, in central Missouri, USA. Corn, soybean, and wheat were cropped in F1 under no-tillage, while corn and soybean were cropped in F3 with tillage. Spring tillage occurred in F3 to an approximate $13 \mathrm{~cm}$ depth one week prior to sensing, and the tilled surface soil was dry and loose. Both F1 and F3 were located on claypan soils, which are distinguished by a greater than $50 \%$ increase in clay from topsoil to subsoil horizons. Measured topsoil depth above the claypan (depth to the first Bt horizon) in these fields ranged from less than $0.1 \mathrm{~m}$ to greater than $1 \mathrm{~m}$ [38]. On claypan soils, variation in the topsoil depth above the restrictive claypan layer leads to variation in hydrology, profile soil properties, and crop productivity. Surface textures at F1 and F3 ranged from silt loam to silty clay loam. The subsoil claypan horizon(s) were silty clay loam, silty clay, or clay, and contained as much as $50-60 \%$ clay. 


\subsection{Sensor Data Collection}

The Veris $\mathrm{P} 4000$ probe included a halogen light source, sapphire window, and spectrometer to collect profile VNIR absorbance (i.e., $\log _{10}[1 /$ reflectance]) spectra (343-2222 nm), dipole contacts for $\mathrm{EC}_{\mathrm{a}}\left(\mathrm{mS} \cdot \mathrm{m}^{-1}\right)$ data collection, and a load cell which quantified $\mathrm{CI}(\mathrm{kPa})$ by measuring the insertion force on the conical tip of the probe (Figure 1). The resolution of the spectrometer was $6 \mathrm{~nm}$ in the spectral range of 342-1023 nm, and $4 \mathrm{~nm}$ in the spectral range of 1070-2220 nm. Depth, EC $\mathrm{E}_{\mathrm{a}} \mathrm{CI}$, and spectra (DECS) were measured simultaneously to a depth of $\sim 1 \mathrm{~m}$. To increase the signal-to-noise ratio through averaging sensor data, probe measurements were repeated five times $\sim 15 \mathrm{~cm}$ apart at each location. All sensor data were obtained at a nominal $20 \mathrm{~Hz}$ rate as the probe was hydraulically inserted into the soil at $\sim 30 \mathrm{~mm} \cdot \mathrm{s}^{-1}$. Instrument output data were the mean of every 25 raw measurements, and each output measurement represented an approximately $4-\mathrm{cm}$ depth increment. Spectral data were visually examined before analysis to identify any near-surface scans that may have been affected by exposure of the detector to sunlight. Any such spectra were deleted prior to analysis, as were data at wavelengths $<400 \mathrm{~nm}$ due to their low signal-to-noise ratio.

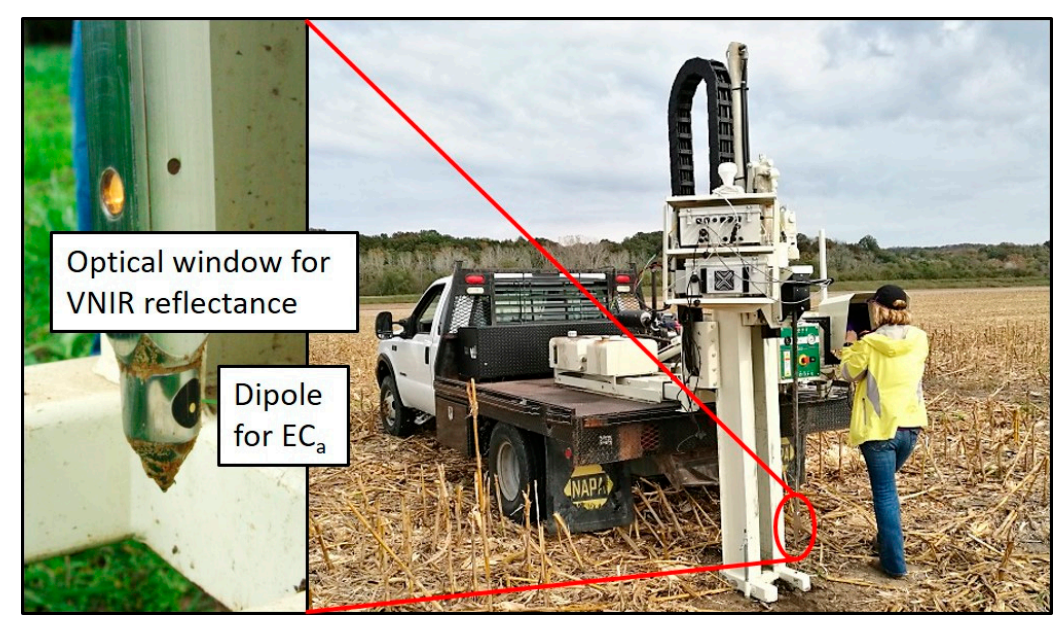

Figure 1. Veris $\mathrm{P} 4000$ instrument in field operation, collecting visible and near-infrared (VNIR) spectra, apparent soil electrical conductivity $\left(\mathrm{EC}_{\mathrm{a}}\right)$, and cone index $(\mathrm{CI})$ penetrometer readings. A close-up view shows the probe tip, including optical window and $\mathrm{EC}_{\mathrm{a}}$ dipole.

\subsection{Soil Sampling and Laboratory Analysis}

To characterize the soil at each location, one $5 \mathrm{~cm}$ diameter soil core was extracted, no further than $0.5 \mathrm{~m}$ from any probe insertion. The soil cores were described and segmented by pedogenic horizon, homogenized with a $5 \mathrm{~mm}$ sieve, then stored in a cooler at $4{ }^{\circ} \mathrm{C}$ until laboratory analysis. The number of horizons per core varied from 2 to 6, with a median of 4 , for a total of 148 horizon samples. In total, profile data and soil cores were obtained from 20 locations in F1 and 13 locations in F3. Soil samples were analyzed for SOC and TN using a Leco TruMac $\mathrm{C} / \mathrm{N}$ combustion analyzer (LECO Corp., St. Joseph, MI, USA), following standard procedures [47]. Samples were analyzed at the University of Missouri Soil Characterization Laboratory for soil texture (clay, silt, and sand fractions; \%), CEC ( $\left.\mathrm{cmol} \cdot \mathrm{kg}^{-1}\right)$, exchangeable cations ( $\mathrm{Ca}, \mathrm{Mg}$, and $\left.\mathrm{K} ; \mathrm{cmol}^{\circ} \mathrm{kg}^{-1}\right)$, and $\mathrm{pH}$ following established methods [48]. Soil moisture was determined gravimetrically.

Table 1 presents the descriptive statistics of the laboratory-measured soil properties. Among profile soil properties, SOC, TN, silt, and Mg varied more than the other properties, with coefficients of variation $(\mathrm{CV})$ greater than $50 \%$. In the surface soil layer, sand, $\mathrm{Ca}, \mathrm{Mg}$, and $\mathrm{K}$ varied the most, with $\mathrm{CV}$ greater than $35 \%$. 
Table 1. Summary statistics of lab-determined soil properties. Coefficient of variation (CV) is in \%.

\begin{tabular}{|c|c|c|c|c|c|c|c|c|c|c|c|c|}
\hline \multirow{2}{*}{ Soil Property } & \multicolumn{4}{|c|}{ Field 1} & \multicolumn{4}{|c|}{ Field 3} & \multicolumn{4}{|c|}{ Combination } \\
\hline & Mean & $\mathrm{SD}^{+}$ & Range & $\mathrm{CV}$ & Mean & SD & Range & $\mathrm{CV}$ & Mean & SD & Range & $\mathrm{CV}$ \\
\hline \multicolumn{13}{|c|}{ Samples from all soil horizons to $1.2 \mathrm{~m}$ profile depth $(\mathrm{n}=148)$} \\
\hline SOC (\%) & 0.69 & 0.40 & 1.29 & 57.3 & 0.74 & 0.48 & $1.59^{\circ}$ & 64.6 & 0.71 & 0.43 & 1.61 & 60.5 \\
\hline $\mathrm{TN}(\%)$ & 0.07 & 0.04 & 0.12 & 54.6 & 0.07 & 0.04 & 0.13 & 64.4 & 0.07 & 0.04 & 0.13 & 58.4 \\
\hline Moisture (\%) & 22.2 & 2.7 & 12.8 & 12.2 & 21.0 & 2.8 & 12.5 & 13.4 & 21.8 & 2.8 & 13.0 & 12.9 \\
\hline Clay fraction $(\%)$ & 35.8 & 14.2 & 47.1 & 39.5 & 33.1 & 11.0 & 43.7 & 33.3 & 34.7 & 13.0 & 47.1 & 37.4 \\
\hline Silt fraction (\%) & 60.6 & 12.5 & 46.5 & 20.6 & 60.9 & 9.1 & 40.0 & 14.9 & 60.7 & 11.2 & 46.5 & 18.4 \\
\hline Sand fraction $(\%)$ & 3.6 & 3.2 & 15.0 & 88.4 & 6.0 & 4.7 & 17.3 & 77.6 & 4.6 & 4.0 & 17.8 & 87.9 \\
\hline $\mathrm{CEC}\left(\mathrm{cmol} \cdot \mathrm{kg}^{-1}\right)$ & 28.2 & 9.2 & 31.7 & 32.5 & 28.0 & 8.2 & 36.6 & 29.4 & 28.1 & 8.8 & 36.6 & 31.2 \\
\hline $\mathrm{Ca}\left(\mathrm{cmol} \cdot \mathrm{kg}^{-1}\right)$ & 10.6 & 3.4 & 18.2 & 31.8 & 14.0 & 3.9 & 19.5 & 28.0 & 12.0 & 4.0 & 21.3 & 33.2 \\
\hline $\mathrm{Mg}\left(\mathrm{cmol} \cdot \mathrm{kg}^{-1}\right)$ & 3.74 & 1.99 & 6.90 & 53.3 & 4.65 & 2.38 & 7.20 & 51.3 & 4.11 & 2.20 & 7.20 & 53.5 \\
\hline $\mathrm{K}\left(\mathrm{cmol} \cdot \mathrm{kg}^{-1}\right)$ & 0.41 & 0.17 & 0.80 & 41.8 & 0.40 & 0.14 & 0.60 & 35.4 & 0.41 & 0.16 & 0.80 & 39.3 \\
\hline $\mathrm{pH}$ & 4.36 & 0.63 & 3.20 & 14.5 & 5.19 & 0.70 & 2.80 & 13.6 & 4.70 & 0.78 & 3.20 & 16.5 \\
\hline \multicolumn{13}{|c|}{ Samples from surface horizon. Depth varied from 8 to $35.7 \mathrm{~cm}$ with a median of $21.8 \mathrm{~cm}(\mathrm{n}=33)$} \\
\hline SOC (\%) & 1.23 & 0.13 & 0.43 & 10.3 & 1.44 & 0.18 & 0.59 & 12.6 & 1.31 & 0.18 & 0.75 & 13.8 \\
\hline TN (\%) & 0.12 & 0.01 & 0.05 & 11.1 & 0.13 & 0.01 & 0.04 & 10.0 & 0.12 & 0.01 & 0.05 & 11.8 \\
\hline Moisture (\%) & 20.6 & 1.27 & 4.2 & 6.2 & 18.7 & 1.9 & 5.36 & 10.1 & 19.83 & 1.78 & 6.56 & 9.0 \\
\hline Clay fraction $(\%)$ & 20.1 & 4.5 & 15.8 & 22.2 & 22.7 & 3.8 & 14.1 & 16.6 & 21.2 & 4.3 & 17.4 & 20.5 \\
\hline Silt fraction $(\%)$ & 73.8 & 5.9 & 21.1 & 8.0 & 69.6 & 4.2 & 13.6 & 6.1 & 72.1 & 5.6 & 22.5 & 7.8 \\
\hline Sand fraction (\%) & 6.1 & 3.0 & 10.8 & 49.7 & 7.7 & 1.6 & 5.10 & 20.8 & 6.7 & 2.6 & 10.8 & 39.1 \\
\hline CEC $\left(\mathrm{cmol} \cdot \mathrm{kg}^{-1}\right)$ & 18.7 & 3.4 & 12.3 & 18.2 & 22.1 & 2.8 & 11.1 & 12.7 & 20.1 & 3.6 & 15.5 & 17.7 \\
\hline $\mathrm{Ca}\left(\mathrm{cmol} \cdot \mathrm{kg}^{-1}\right)$ & 9.6 & 4.0 & 17.9 & 41.1 & 15.0 & 2.17 & 8.0 & 14.5 & 11.8 & 4.3 & 17.9 & 36.0 \\
\hline $\mathrm{Mg}\left(\mathrm{cmol} \cdot \mathrm{kg}^{-1}\right)$ & 1.55 & 0.68 & 2.80 & 43.7 & 2.14 & 0.71 & 2.30 & 33.0 & 1.79 & 0.74 & 2.80 & 41.2 \\
\hline $\mathrm{K}\left(\mathrm{cmol} \cdot \mathrm{kg}^{-1}\right)$ & 0.25 & 0.08 & 0.20 & 30.6 & 0.44 & 0.13 & 0.40 & 30.2 & 0.33 & 0.14 & 0.50 & 41.9 \\
\hline $\mathrm{pH}$ & 5.16 & 0.76 & 2.90 & 14.7 & 6.22 & 0.32 & 1.10 & 5.1 & 5.59 & 0.81 & 2.90 & 14.4 \\
\hline
\end{tabular}

${ }^{\dagger} \mathrm{SD}=$ standard deviation, $\mathrm{CV}=$ coefficient of variation, $\mathrm{SOC}=$ soil organic carbon, $\mathrm{TN}=$ total nitrogen, $\mathrm{CEC}=$ cation exchange capacity, $\mathrm{Ca}=$ calcium, $\mathrm{Mg}=$ magnesium, $\mathrm{K}$ = potassium.

\subsection{Alignment of Soil and Sensor Data}

Because soil and sensor data (spectra, $\mathrm{EC}_{\mathrm{a}}$, and $\mathrm{CI}$ ) were collected at different depth increments, it was necessary to combine them to a common level of spatial (i.e., vertical) support. This was done using weighted averaging of the sensor data to match the soil samples segmented by variable thickness horizons from the soil cores. The weighting procedure was based on the fact that the sensor depth recorded was the final depth of the instrument at the end of the 25-scan observation period. This depth then defined the starting depth for the next observation in the probing sequence. These sensor-data depth segments varied in thickness, with an average thickness of $4.1 \mathrm{~cm}$ and a standard deviation of $1.4 \mathrm{~cm}$. The initial starting depth for the first observation in any probe was unknown. Therefore, we chose to start at a depth of zero for the first scan, or at a depth such that the first observation represented no more than $4.0 \mathrm{~cm}$ of depth. Observations that fell entirely into a single soil layer were weighted by the depth increment of the observation divided by the total thickness of the layer. Where observations spanned two soil layers, the observation was partitioned into both layers based on the amount of depth represented in each layer and again divided by layer thickness. At the end of this procedure, the weighted average sensor data were merged with the corresponding soil properties. Observations with missing laboratory or sensor data were dropped, resulting in a final dataset of 148 observations for analysis.

\subsection{Analysis Methods}

Different combinations of spectral preprocessing techniques, sensor data sources, and modeling methods were evaluated and compared to select the best combination for in-situ estimation of profile soil properties. The procedure included: (1) comparison of ten spectral preprocessing techniques for PLSR analysis of the DECS dataset; (2) using the best preprocessing technique and PLSR, comparing DECS and VNIR spectra results; (3) using DECS and the best preprocessing technique, comparison of results from four modeling methods (detailed below); and (4) comparison of calibration models 
developed for a single field with those developed for multiple fields. Model evaluation was based on coefficient of determination $\left(R^{2}\right)$ and RMSE calculated in the validation dataset.

One consideration in preparing the DECS dataset was whether the scalar variables (i.e., depth, $\mathrm{EC}_{\mathrm{a}}$, and $\mathrm{CI}$ ) should receive additional weighting to compensate for the effect of many variables $(n=374)$ in the spectral data vector. The use of this preprocessing step, known as block scaling in PLSR analysis [49], has been investigated on other datasets collected using the P4000 instrument [26,27]. In these previous studies there was no consistent relationship between the block scaling (or weighting) factor and estimation accuracy, with one reporting a significant relationship between RMSE of prediction and magnitude of the scaling factor in only two of 36 cases [26]. Therefore, block scaling was not implemented in this study.

\subsubsection{Spectral Preprocessing}

After screening a larger number of preprocessing techniques on a preliminary dataset, ten different techniques were applied to the spectra in Matlab 2016 (Mathworks, Inc., Natick, MA, USA) and the results were compared:

(1) Reflectance spectra (transformed from absorbance to reflectance);

(2) Absorbance spectra (the default output format of the P4000 instrument);

(3) Mean normalized spectra, smoothed with a 9-point moving average;

(4) Spectra smoothed with a 9-point moving average and then mean normalized;

(5) 30-point moving average;

(6) 30-point Lowess smoothing;

(7) 30-point Gaussian window smoothing;

(8) 30-point Exponential smoothing;

(9) Standard normal variate (SNV) transformation;

(10) SNV plus 30-point Gaussian smoothing.

Absorbance spectra, the default output of the P4000 instrument, and the standard transformation from absorbance to reflectance (techniques 2 and 1, respectively), were evaluated without further preprocessing. The remaining preprocessing techniques (3-10) were applied to the absorbance spectra, including various normalization and moving average smoothing techniques commonly used in soil DRS sensing $[1,9,10,26]$. Techniques 5-8 applied various smoothing windows to the non-normalized absorbance spectra. Lowess smoothing (locally weighted scatterplot smoothing) was developed to use locally weighted linear regression to smooth data [50,51]. Gaussian window smoothing applied a Gaussian-weighted moving average. In the exponential smoothing method, the moving average was exponentially weighted. Technique 9 applied the standard normal variate (SNV) transformation to remove baseline effects due to scatter and particle size [52], while technique 10 combined SNV with 30-point Gaussian smoothing.

\subsubsection{Calibration Methods}

Based on a review of past work and preliminary analysis of a larger set of methods on a previous dataset, four calibration methods were chosen for evaluation on the DECS dataset. These were PLSR, neural networks $(\mathrm{NN})$, regression trees $(\mathrm{RT})$, and random forests $(\mathrm{RF})$.

Partial least squares regression is a statistical method that finds a linear regression model by projecting the dependent and independent variables to a new space. A new set of uncorrelated variables, called factors, was created to explain the variation of predictor and response variables [53]. For high dimensional data, PLSR can estimate the importance of features, and choose the optimal number of factors without overfitting. For spectral analysis, all wavelengths can be used for developing a calibration algorithm. For this study, PLSR was implemented in Unscrambler 10.4 (CAMO Inc., Oslo, Norway) with a random cross-validation method to select the optimum number of factors up to a maximum of 15. 
The NN approach was implemented with the Neural Network Fitting Tool of Matlab 2016. Neural networks are inspired by biological nervous systems and consist of simple elements, which work in parallel. As in nature, the connections between elements largely determine NN function, and can be trained to implement a particular function by adjusting the values of the connections (weights) between elements. Ideally, a NN is able to predict a particular target after proper training. In this study, the Neural Network Fitting Tool was used to build NN by modifying example code to import spectra and soil properties. Data were divided into three subsets: $70 \%$ to train the network, $15 \%$ to validate network generalization and to stop training before overfitting, and $15 \%$ to test the performance of the trained network when predicting to a new dataset.

Regression trees and RF were implemented in IBM SPSS Modeler 18.0 (IBM Inc., Armonk, NY, USA). Standard regression methods assume a parametric relationship between the response and predictor variables (e.g., linear, quadratic). In contrast, RT construct a set of decision rules based on the predictor variables [54-56]. The data are recursively divided into smaller groups by binary splits based on a single predictor variable. The splits are chosen to maximize the homogeneity of the two resulting groups. The result of RT is a tree diagram with the branches determined by the splitting rules. The maximal tree is grown first, then the trees are pruned to an optimal size by techniques such as cross-validation [57]. For this study, $70 \%$ of the data were used for training and $30 \%$ for prediction. A single tree was built with a maximum tree depth of five. The tree was pruned by cross-validation to avoid overfitting.

A RF is a collection of decision trees, regression trees in this case, where a subset of the data is selected randomly for each decision tree that is part of the RF. This concept uses a combination of tree predictors, each depending on a randomly selected subset of data [58]. Specifically, the split at each node is determined using the best split of all variables in the standard trees, using internal estimates to evaluate the importance of each variable. This method is typically robust, performs well, and is user-friendly. In this study, 100 models were built with the maximum number of nodes set to 10,000 . The maximum regression tree depth was ten and the maximum number of child nodes was five. As was done for RT, $70 \%$ of the data were used for training and 30\% for prediction. Building was terminated when accuracy no longer improved.

For all calibration methods, division into training and prediction sets was done randomly by sample. It has been previously suggested [59] that such division instead be done by location, i.e., keeping the samples for all depths at a given location together. We recognize that from a theoretical standpoint, our analysis methods could produce overly optimistic results in the presence of spatially correlated soil properties. However, due to lateral spatial correlation, the same could be said, although perhaps to a lesser extent, if by-location selection was employed. When the two selection procedures were compared previously, the difference between them was generally small when $>50 \%$ of the samples were used for calibration [59].

To understand the differences in our dataset, we conducted a limited analysis, comparing by-sample and by-location selection when using PLSR and NN models, and finding little consistency in results. For NN analysis, by-sample results were better for 7 of 11 soil properties, while PLSR by-sample results were better in only 3 of 11 cases. Thus, our data did not strongly support the need for by-location validation set selection. This may be due in part to our depth-sampling procedure based on soil horizons rather than the fixed depth increments used in [59], which may have reduced vertical spatial correlation in our dataset. Based on these results, we proceeded with by-sample selection, recognizing the need to more rigorously investigate this question in the future.

\section{Results and Discussion}

Multiple spectral preprocessing techniques, sensor data sources, and modeling methods were evaluated and compared to select the best combination for in-situ estimation of profile soil properties. Detailed results are provided in the sections below. 


\subsection{Comparison of Spectral Preprocessing Techniques}

The complex field environment, including variable temperature and soil moisture conditions, is known to impact the accuracy of in-situ sensor measurements. Various preprocessing techniques have the potential to improve the accuracy of in-situ measurements. Here, ten different preprocessing techniques were applied to spectral data, and multiple soil properties were subsequently estimated using DECS and PLSR. Table 2 shows summary statistics for prediction $\mathrm{R}^{2}$ for each spectral preprocessing technique across all soil properties. Results are presented for three datasets: F1, F3, and the combination of F1 and F3. When averaged across the three datasets, the grand (i.e., overall) mean prediction $R^{2}$ was very similar for all preprocessing techniques, ranging from 0.58 to 0.61 , with the 30-point Gaussian window smoothing and SNV plus Gaussian performing the best $\left(R^{2}=0.61\right)$, followed by the 30-point moving average and SNV $\left(R^{2}=0.60\right)$. Thus, when averaged across all variables and datasets, no single pretreatment was clearly better than the other.

Table 2. Prediction $\mathrm{R}^{2}$ summary statistics for models using different spectral preprocessing techniques and calculated with partial least squares regression (PLSR) applied to the combined dataset including depth, $\mathrm{EC}_{\mathrm{a}}, \mathrm{CI}$, and spectra (DECS) for the individual fields and the combined field dataset. For each preprocessing technique and dataset, $\mathrm{R}^{2}$ statistics were across models for all soil properties. Grand mean $\mathrm{R}^{2}$ is the mean of the three datasets. Coefficient of variation $(\mathrm{CV})$ is in \%.

\begin{tabular}{|c|c|c|c|c|c|c|c|c|c|c|}
\hline \multirow{2}{*}{$\begin{array}{l}\text { Preprocessing } \\
\text { Technique }\end{array}$} & \multicolumn{3}{|c|}{ Field 1} & \multicolumn{3}{|c|}{ Field 3} & \multicolumn{3}{|c|}{$\begin{array}{l}\text { Combination } \\
\text { (F1 + F3) }\end{array}$} & \multirow{2}{*}{$\begin{array}{c}\text { Grand } \\
\text { Mean } \mathbf{R}^{2}\end{array}$} \\
\hline & Mean & $\begin{array}{l}\mathrm{SD}^{+} \& \\
\text { Range }\end{array}$ & $\mathrm{CV}$ & Mean & $\begin{array}{c}\text { SD \& } \\
\text { Range }\end{array}$ & $\mathrm{CV}$ & Mean & $\begin{array}{c}\text { SD \& } \\
\text { Range }\end{array}$ & $\mathrm{CV}$ & \\
\hline Reflectance & 0.51 & $\begin{array}{l}0.14 \\
0.44\end{array}$ & 28.1 & 0.65 & $\begin{array}{l}0.16 \\
0.51\end{array}$ & 24.9 & 0.57 & $\begin{array}{l}0.15 \\
0.48\end{array}$ & 25.3 & 0.58 \\
\hline Absorbance & 0.52 & $\begin{array}{l}0.14 \\
0.43\end{array}$ & 26.8 & 0.67 & $\begin{array}{l}0.15 \\
0.49\end{array}$ & 23.1 & 0.59 & $\begin{array}{l}0.16 \\
0.49\end{array}$ & 27.4 & 0.59 \\
\hline Normalize + 9-point m.a. & 0.51 & $\begin{array}{l}0.14 \\
0.45\end{array}$ & 28.2 & 0.65 & $\begin{array}{l}0.18 \\
0.54\end{array}$ & 27.3 & 0.61 & $\begin{array}{l}0.20 \\
0.70\end{array}$ & 32.6 & 0.59 \\
\hline $\begin{array}{l}\text { 9-point m.a. } \\
\text { then normalize }\end{array}$ & 0.52 & $\begin{array}{l}0.13 \\
0.39\end{array}$ & 25.8 & 0.62 & $\begin{array}{l}0.18 \\
0.55\end{array}$ & 28.4 & 0.59 & $\begin{array}{l}0.14 \\
0.45\end{array}$ & 24.1 & 0.58 \\
\hline 30-point m.a. & 0.53 & $\begin{array}{l}0.13 \\
0.38\end{array}$ & 24.6 & 0.68 & $\begin{array}{l}0.14 \\
0.44\end{array}$ & 21.0 & 0.59 & $\begin{array}{l}0.16 \\
0.50\end{array}$ & 27.9 & 0.60 \\
\hline $\begin{array}{c}\text { 30-point } \\
\text { Lowess smoothing }\end{array}$ & 0.52 & $\begin{array}{l}0.15 \\
0.50\end{array}$ & 28.8 & 0.65 & $\begin{array}{l}0.16 \\
0.48\end{array}$ & 25.3 & 0.60 & $\begin{array}{l}0.16 \\
0.47\end{array}$ & 25.8 & 0.59 \\
\hline $\begin{array}{c}\text { 30-point } \\
\text { Gaussian smoothing }\end{array}$ & 0.51 & $\begin{array}{l}0.15 \\
0.53\end{array}$ & 29.8 & 0.71 & $\begin{array}{l}0.12 \\
0.40\end{array}$ & 16.9 & 0.60 & $\begin{array}{l}0.16 \\
0.47\end{array}$ & 26.0 & 0.61 \\
\hline $\begin{array}{c}\text { 30-point } \\
\text { exponential smoothing }\end{array}$ & 0.52 & $\begin{array}{l}0.13 \\
0.42\end{array}$ & 25.7 & 0.64 & $\begin{array}{l}0.17 \\
0.47\end{array}$ & 26.2 & 0.60 & $\begin{array}{l}0.15 \\
0.45\end{array}$ & 24.2 & 0.59 \\
\hline $\begin{array}{l}\text { SNV (standard } \\
\text { normal variate) }\end{array}$ & 0.52 & $\begin{array}{l}0.16 \\
0.42\end{array}$ & 29.9 & 0.68 & $\begin{array}{l}0.14 \\
0.43\end{array}$ & 27.4 & 0.61 & $\begin{array}{l}0.14 \\
0.44\end{array}$ & 23.7 & 0.60 \\
\hline $\begin{array}{c}\text { SNV + 30-pt } \\
\text { Gaussian smoothing }\end{array}$ & 0.54 & $\begin{array}{l}0.15 \\
0.39\end{array}$ & 27.4 & 0.68 & $\begin{array}{l}0.14 \\
0.44\end{array}$ & 20.2 & 0.61 & $\begin{array}{l}0.15 \\
0.46\end{array}$ & 24.0 & 0.61 \\
\hline
\end{tabular}

${ }^{\dagger} \mathrm{SD}=$ standard deviation, $\mathrm{CV}=$ coefficient of variation, m.a. = moving average.

The prediction statistics of individual soil properties for each spectral preprocessing technique are shown in Table 3. These results are for the combined (F1 and F3) dataset analyzed using DECS and PLSR. Absorbance spectra performed better than reflectance spectra for all soil properties except for soil moisture $\left(R^{2}=0.33\right.$ and 0.43 , respectively) and clay content $\left(R^{2}=0.54\right.$ and 0.60 , respectively). Across the individual soil properties, the 30-point Gaussian window smoothing technique performed the best for four of the eleven soil properties (CEC, $\mathrm{Ca}, \mathrm{Mg}$, and $\mathrm{pH}$ ), and was not one of the two worst preprocessing techniques for any soil property. The next best technique, SNV, also performed the best for the four soil properties (SOC, TN, moisture, and sand), but was one of the two worst techniques for $\mathrm{Ca}$. Generally, there was very little difference in estimation accuracy between these top two preprocessing techniques, with $\Delta \mathrm{R}^{2}<0.01$ for all but two soil properties. As the (marginally) best 
preprocessing technique of those evaluated, the 30-point Gaussian window smoothing was selected for use in subsequent analyses.

Table 3. Fit statistics for soil property estimation with each preprocessing technique, calculated with partial least squares regression (PLSR) and cross-validation on the combined dataset including depth, $\mathrm{EC}_{\mathrm{a}}, \mathrm{CI}$, and spectra (DECS). For each cell, the top row is $\mathrm{R}^{2}$ and the bottom row is root mean square error (RMSE; see Table 1 for units). Bold entries denote the highest $\mathrm{R}^{2}$ for each soil property, while underlined entries are the two lowest for each property.

\begin{tabular}{|c|c|c|c|c|c|c|c|c|c|c|c|}
\hline $\begin{array}{c}\text { Preprocessing } \\
\text { Technique }\end{array}$ & $\mathrm{SOC}^{+}$ & TN & Moisture & Clay & Silt & Sand & CEC & $\mathrm{Ca}$ & $\mathrm{Mg}$ & $\mathbf{K}$ & pH \\
\hline \multirow{2}{*}{ Reflectance } & 0.78 & 0.76 & 0.43 & 0.60 & 0.54 & 0.31 & 0.60 & 0.49 & 0.79 & 0.48 & 0.57 \\
\hline & $\overline{0.204}$ & $0 . \overline{0201}$ & 2.103 & 8.264 & 7.638 & $\overline{3.360}$ & $\overline{5.560}$ & $\overline{2.839}$ & 1.005 & 0.117 & $\overline{0.506}$ \\
\hline \multirow{2}{*}{ Absorbance } & 0.79 & 0.77 & $\underline{0.33}$ & 0.57 & 0.56 & 0.32 & 0.65 & 0.62 & 0.81 & 0.48 & 0.66 \\
\hline & 0.198 & 0.0198 & 2.312 & 8.521 & 7.441 & 3.347 & 5.184 & 2.431 & 0.978 & 0.116 & 0.456 \\
\hline Normalize then & 0.79 & 0.76 & 0.38 & $\underline{0.57}$ & $\underline{0.45}$ & $\underline{0.29}$ & 0.61 & 0.62 & 0.80 & 0.47 & 0.63 \\
\hline 9-point m.a. & 0.195 & 0.0199 & 2.205 & $\overline{8.493}$ & 8.265 & $\overline{3.411}$ & 5.508 & 2.453 & 0.982 & 0.118 & 0.476 \\
\hline 9-point m.a. & 0.80 & 0.76 & 0.39 & $\underline{0.55}$ & 0.53 & 0.35 & $\underline{0.58}$ & 0.61 & $\underline{0.76}$ & 0.49 & 0.65 \\
\hline then normalize & 0.194 & 0.0198 & 2.202 & $\overline{8.755}$ & 7.654 & 3.267 & $\overline{5.688}$ & 2.485 & $\overline{1.081}$ & 0.116 & 0.462 \\
\hline \multirow{2}{*}{ 30-point m.a. } & 0.79 & 0.76 & $\underline{0.31}$ & 0.61 & $\underline{0.51}$ & 0.34 & 0.64 & 0.63 & 0.81 & $\underline{0.43}$ & $\underline{0.62}$ \\
\hline & 0.199 & 0.0198 & 2.333 & 8.130 & $\overline{7.825}$ & 3.282 & 5.261 & 2.438 & 0.977 & 0.122 & $\overline{0.479}$ \\
\hline 30-point & 0.80 & 0.76 & 0.36 & 0.59 & 0.56 & 0.34 & 0.63 & 0.64 & 0.81 & $\underline{0.44}$ & 0.65 \\
\hline Lowess smoothing & 0.196 & 0.0197 & 2.439 & 8.425 & 7.429 & 3.274 & 5.300 & 2.414 & 0.958 & $\overline{0.120}$ & 0.462 \\
\hline 30-point & 0.80 & 0.77 & 0.37 & 0.58 & 0.52 & 0.34 & 0.65 & 0.64 & 0.81 & 0.46 & 0.67 \\
\hline Gaussian smoothing & 0.194 & 0.0196 & 2.240 & 8.421 & 7.774 & 3.265 & 5.246 & 2.424 & 0.961 & 0.117 & 0.450 \\
\hline 30-point & 0.79 & 0.76 & 0.40 & 0.61 & 0.54 & 0.35 & 0.62 & 0.63 & 0.80 & 0.45 & 0.65 \\
\hline exponential smoothing & $\overline{0.198}$ & $0 . \overline{0200}$ & 2.180 & 8.147 & 7.579 & 3.270 & 5.379 & 2.461 & 0.985 & 0.119 & 0.463 \\
\hline SNV (standard & 0.81 & 0.78 & 0.48 & 0.62 & 0.55 & 0.37 & 0.63 & $\underline{0.58}$ & 0.79 & 0.45 & 0.65 \\
\hline normal variate) & 0.188 & 0.0193 & 2.020 & 8.000 & 7.544 & 3.230 & 5.386 & 2.594 & 1.008 & 0.118 & 0.457 \\
\hline $\mathrm{SNV}+30-\mathrm{pt}$ & 0.81 & 0.77 & 0.48 & 0.63 & 0.54 & 0.35 & 0.61 & 0.63 & $\underline{0.78}$ & 0.44 & 0.66 \\
\hline Gaussian smoothing & 0.186 & 0.0196 & 2.040 & 7.868 & 7.556 & 3.248 & 5.479 & 2.426 & $\overline{1.020}$ & 0.119 & 0.460 \\
\hline
\end{tabular}

\subsection{Comparison of Spectra and DECS}

The combined F1 and F3 DECS dataset was compared to the dataset containing only spectra to investigate if the additional information from DECS improved estimation of soil properties. It was expected that each of the auxiliary sensors might improve results for at least some of the soil properties. For example, soil properties are known to vary with depth, so the depth measurement might be important. Soil $\mathrm{EC}_{\mathrm{a}}$ has been correlated with soil moisture, clay content, CEC, and other soil properties [38-40]. As a measure of soil penetration resistance, CI [41,42] has been found highly correlated with soil moisture, clay content, and BD [43-45]. Table 4 summarizes the results of this comparison. Across all soil properties, the average prediction $\mathrm{R}^{2}$ of spectra and DECS was 0.58 and 0.59 , respectively. Overall, DECS performed slightly better than spectra for silt, sand, CEC, Ca, and Mg. However, RMSE with DECS decreased by more than 5\% only for Ca compared to spectra alone. Spectra alone performed slightly better for TN, moisture, clay content, and $\mathrm{K}$, while results for SOC and $\mathrm{pH}$ were the same with both datasets. These results are in accordance with other studies [26,27], where additional sensor data only slightly improved accuracy compared to spectra alone, or in some cases, provided less accurate estimates. It appears, at least for these soils, that additional variables do not provide much explanatory information that is not already contained within the spectra. However, the additional data contained in the DECS dataset might provide improved results for different soils, or for a dataset containing more variation in soil types than was present in this study or other previous research $[26,27]$. This should be a subject of future investigation. 
Table 4. Fit statistics for soil property estimation with spectra alone, or the combination of depth, electrical conductivity, cone index, and spectra (DECS), calculated with partial least squares regression (PLSR) and cross-validation on the combined Field 1 and Field 3 dataset. For each cell, the top row is $\mathrm{R}^{2}$ and the bottom row is root mean square error (RMSE; see Table 1 for units).

\begin{tabular}{cccccccccccc}
\hline & SOC $^{+}$ & TN & Moisture & Clay & Silt & Sand & CEC & Ca & Mg & K & pH \\
\hline \multirow{2}{*}{ Spectra } & 0.80 & 0.78 & 0.39 & 0.61 & 0.54 & 0.27 & 0.60 & 0.52 & 0.79 & 0.45 & 0.66 \\
& 0.193 & 0.019 & 2.218 & 8.089 & 7.626 & 3.468 & 5.536 & 2.795 & 1.011 & 0.118 & 0.453 \\
\multirow{2}{*}{ DECS } & 0.80 & 0.77 & 0.34 & 0.57 & 0.54 & 0.34 & 0.63 & 0.62 & 0.80 & 0.44 & 0.66 \\
& 0.193 & 0.020 & 2.281 & 8.551 & 7.557 & 3.297 & 5.337 & 2.439 & 0.989 & 0.121 & 0.453 \\
\hline
\end{tabular}

${ }^{+} \mathrm{SOC}=$ soil organic carbon, $\mathrm{TN}=$ total nitrogen, $\mathrm{CEC}=$ cation exchange capacity, $\mathrm{Ca}=$ calcium, $\mathrm{Mg}=$ magnesium, $\mathrm{K}=$ potassium.

\subsection{Model Calibration Methods}

Multiple calibration modeling methods (i.e., PLSR, NF, RT, and RF) were compared for the estimation of soil properties. The PLSR method was either the most accurate or the second most accurate method for each of the soil properties (Figure 2). The average $\mathrm{R}^{2}$ values across all soil properties for PLSR, NN, RT, and RF were $0.59,0.46,0.39$, and 0.45 , respectively. When looking at individual soil properties, PLSR results were best for six of 11 (soil moisture, $\mathrm{CEC}, \mathrm{Ca}, \mathrm{Mg}, \mathrm{K}$, and $\mathrm{pH}$ ). Neural network results were best for SOC, TN, and silt, while RF performed the best for clay and sand. The lowest $\mathrm{R}^{2}$ values were consistently produced by the RT method, with some RT analyses not converging to a solution. In addition to the six soil properties where it gave the best results, PLSR was the second-best performing for four other properties (SOC, TN, clay, and silt) where $\mathrm{R}^{2}$ with PLSR was within $10 \%$ of the best method. Therefore, PLSR was selected as the most robust calibration method with DECS, and was used for subsequent analysis.

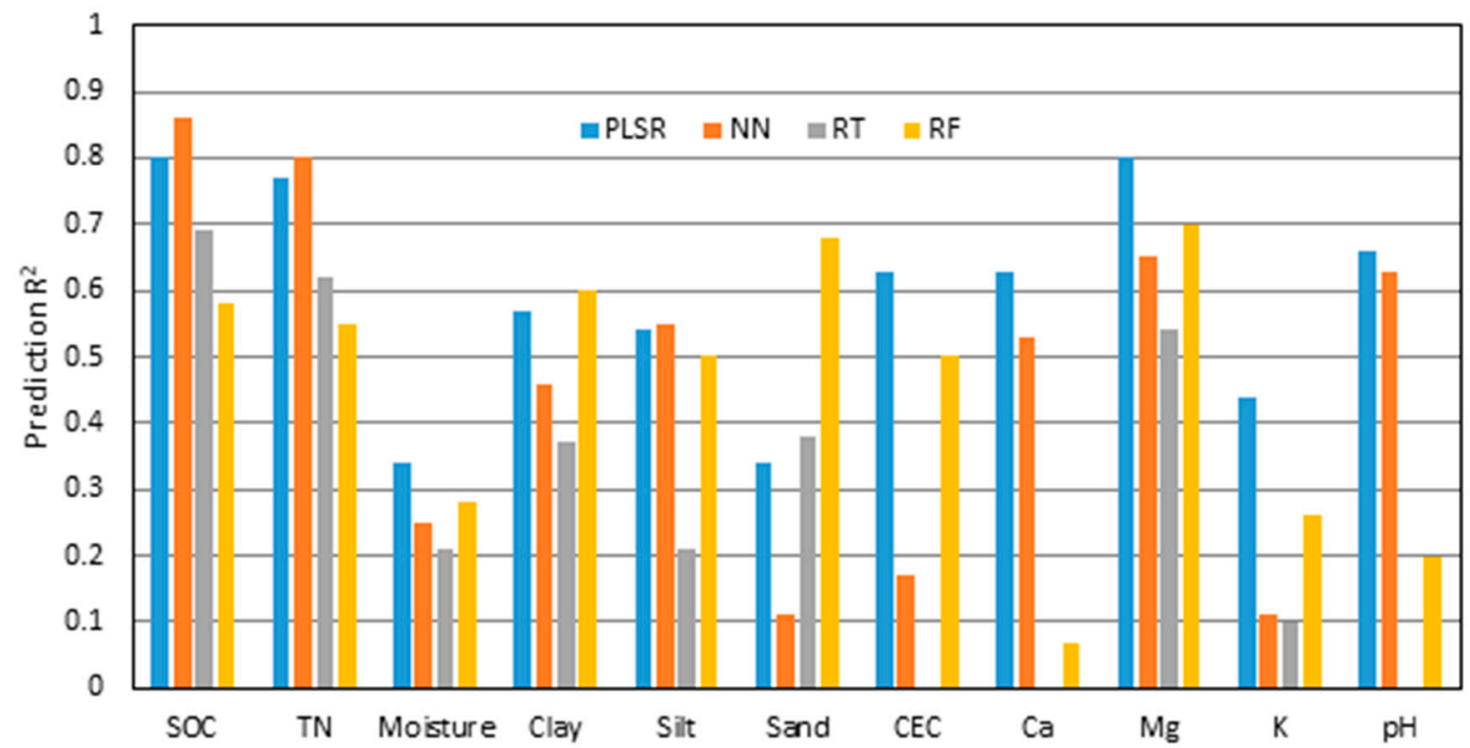

Figure 2. Prediction $\mathrm{R}^{2}$ values comparing results obtained on the combined Field 1 and Field 3 depth, $\mathrm{EC}_{\mathrm{a}}, \mathrm{CI}$ and spectra (DECS) dataset using partial least squares regression (PLSR), neural networks $(\mathrm{NN})$, regression trees $(\mathrm{RT})$, and random forests $(\mathrm{RF})$ methods. Missing bars indicate that analysis did not converge to a solution.

\subsection{Comparison Among Fields}

To examine the performance of DECS and PLSR at the field scale, the data from F1 and F3 were analyzed independently and compared. Soils and conditions of the two fields were similar at the time of sampling and data collection, except F3 was tilled approximately one week prior to measurement 
and the surface soil was loose and somewhat drier. Mean soil moisture in the surface horizon was $20.6 \%$ for F1 and $18.7 \%$ for F3. The profile soil moisture of F1 varied from $18.5 \%$ to $22.7 \%$ with a median of $20.6 \%$, while the profile soil moisture of F3 varied from $16.1 \%$ to $21.5 \%$ with a median of $18.7 \%$. For all soil properties except silt, the estimation accuracy for F3 was better than for F1 (Figure 3). For most soil properties, the estimation accuracy for the dataset including both fields was intermediate to that of F1 and F3. Exceptions were for silt fraction and K, where accuracy for all three datasets was similar, and for sand fraction (Figure 3).

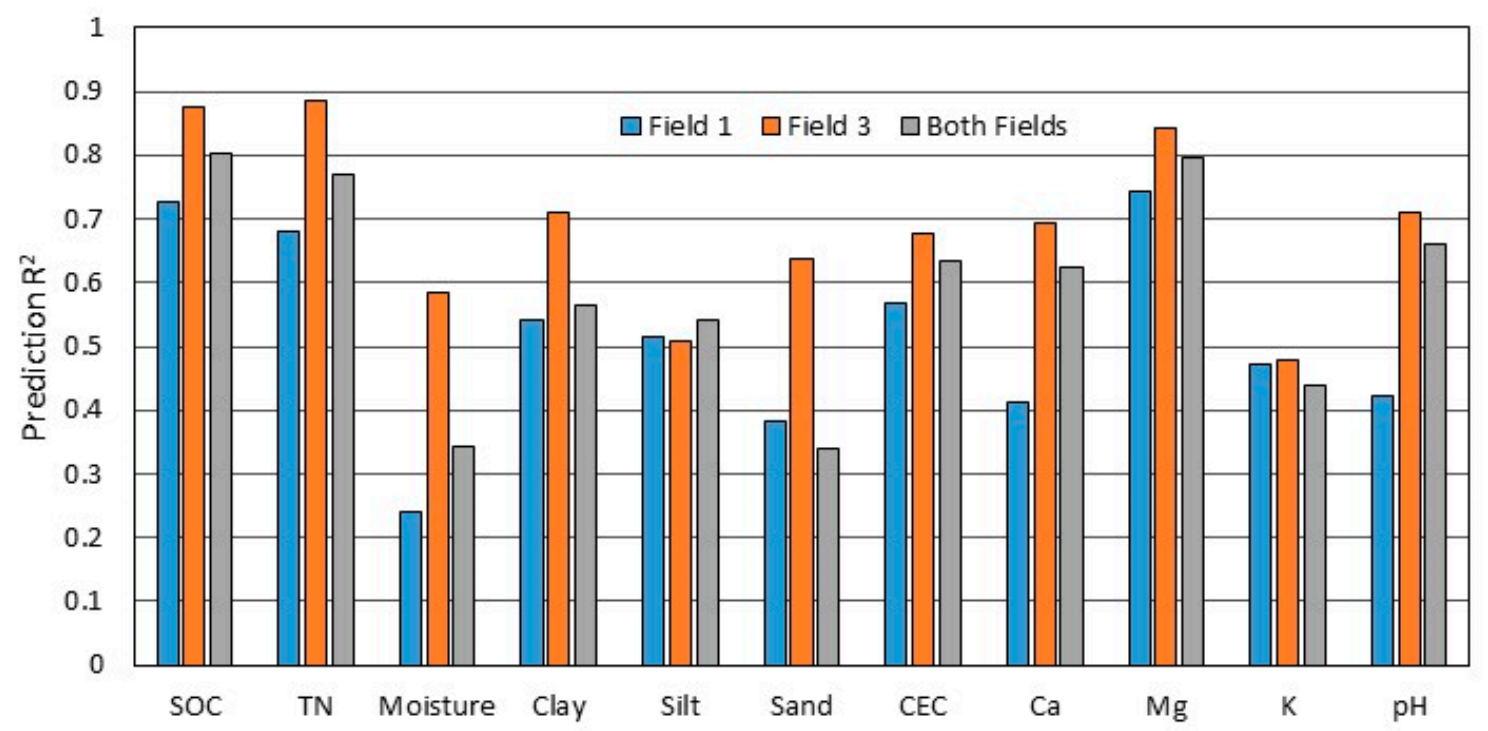

Figure 3. Prediction $R^{2}$ values comparing results from Field 1, Field 3, and the combination of both fields using partial least squares regression (PLSR) on the combined dataset including depth, EC, $\mathrm{CI}$ and spectra (DECS).

A comparison of prediction $\mathrm{R}^{2}$ and RMSE across all soil properties for F1, F3, and the combination of F1 and F3 is shown in Table 5. Generally, estimation accuracy was better for F3 than F1, or the combination of F1 and F3. For each field and the combination, some soil properties were estimated more accurately by DECS and others by spectra alone, although in general the differences were slight. The only relatively large changes in $\mathrm{R}^{2}$ (magnitude $>0.05$ ) were for $\mathrm{TN}$, soil moisture, and Ca in F1, moisture, silt, sand, and Ca in F3, and Ca in the combination dataset. Averaged across all soil properties, there was an increase in $\mathrm{R}^{2}$ of 0.03 and 0.01 with DECS for F3 and the combination, respectively, while there was a decrease of 0.01 with DECS for F1. There was little consistency across the datasets as to whether DECS or spectra were better. A notable exception was for Ca, where DECS was considerably better than spectra alone in all three datasets, likely due to $\mathrm{EC}_{\mathrm{a}}$ responding to the clay mineralogy. Smectitic clay minerals such as montmorillonite dominate in this region [60]. These expandable clays exhibit high surface area and charge characteristics that increase the holding capacity for positively charged ions such as calcium [61,62] and likely contribute to the $\mathrm{EC}_{\mathrm{a}}$ response.

In general, we note that vertical and lateral spatial correlation, which was not accounted for in our analyses, may have caused overestimation of model performance. However, in a study like this, where the main objective is a comparison of methods (i.e., for modeling, preprocessing, and dataset selection), it seems likely that the results and conclusions regarding the outcome of the comparisons would be similar given that the same validation set selection approach was used consistently. On the other hand, if the goal was to develop robust calibrations suitable for application to unsampled locations, different sample selection approaches [59] might be recommended. 
Table 5. Prediction $\mathrm{R}^{2}$ and root mean square error (RMSE) calculated with different field data using the combination of depth, $\mathrm{EC}_{\mathrm{a}}, \mathrm{CI}$ and spectra (DECS) and spectra alone. See Table 1 for units of RMSE. For each soil property within each field or the combination of both fields, bold text highlights the best $\mathrm{R}^{2}$ and RMSE.

\begin{tabular}{|c|c|c|c|c|c|c|c|c|c|c|c|c|}
\hline \multirow{3}{*}{ Soil Property } & \multicolumn{4}{|c|}{ Field 1} & \multicolumn{4}{|c|}{ Field 3} & \multicolumn{4}{|c|}{ Combination } \\
\hline & \multicolumn{2}{|c|}{ DECS } & \multicolumn{2}{|c|}{ Spectra } & \multicolumn{2}{|c|}{ DECS } & \multicolumn{2}{|c|}{ Spectra } & \multicolumn{2}{|c|}{ DECS } & \multicolumn{2}{|c|}{ Spectra } \\
\hline & $\mathbf{R}^{2}$ & RMSE & $\mathbf{R}^{2}$ & RMSE & $\mathbf{R}^{2}$ & RMSE & $\mathbf{R}^{2}$ & RMSE & $\mathbf{R}^{2}$ & RMSE & $\mathbf{R}^{2}$ & RMSE \\
\hline $\mathrm{SOC}^{+}$ & 0.73 & 0.208 & 0.77 & 0.194 & 0.87 & 0.173 & 0.87 & 0.177 & 0.80 & 0.193 & 0.80 & 0.193 \\
\hline $\mathrm{TN}$ & 0.68 & 0.022 & 0.73 & 0.020 & 0.89 & 0.015 & 0.85 & 0.017 & 0.77 & 0.020 & 0.78 & 0.019 \\
\hline Moisture & 0.24 & 2.387 & 0.34 & 2.210 & 0.59 & 1.838 & 0.49 & 1.979 & 0.34 & 2.281 & 0.39 & 2.218 \\
\hline Clay & 0.54 & 9.687 & 0.55 & 9.463 & 0.71 & 6.007 & 0.72 & 5.834 & 0.57 & 8.551 & 0.61 & 8.089 \\
\hline Silt & 0.52 & 8.627 & 0.53 & 8.647 & 0.51 & 6.377 & 0.60 & 5.802 & 0.54 & 7.557 & 0.54 & 7.626 \\
\hline Sand & 0.38 & 2.502 & 0.38 & 2.516 & 0.64 & 2.862 & 0.74 & 2.453 & 0.34 & 3.297 & 0.27 & 3.468 \\
\hline CEC & 0.57 & 6.055 & 0.55 & 6.157 & 0.68 & 4.682 & 0.70 & 4.625 & 0.63 & 5.337 & 0.60 & 5.536 \\
\hline $\mathrm{Ca}$ & 0.41 & 2.587 & 0.26 & 2.920 & 0.70 & 2.232 & 0.55 & 2.642 & 0.63 & 2.439 & 0.52 & 2.795 \\
\hline $\mathrm{Mg}$ & 0.74 & 1.019 & 0.75 & 1.003 & 0.84 & 0.959 & 0.80 & 1.066 & 0.80 & 0.989 & 0.79 & 1.011 \\
\hline K & 0.47 & 0.127 & 0.46 & 0.129 & 0.48 & 0.103 & 0.28 & 0.120 & 0.44 & 0.121 & 0.45 & 0.118 \\
\hline $\mathrm{pH}$ & 0.42 & 0.487 & 0.45 & 0.470 & 0.71 & 0.381 & 0.71 & 0.386 & 0.66 & 0.453 & 0.66 & 0.453 \\
\hline
\end{tabular}

${ }^{+} \mathrm{SOC}=$ soil organic carbon, $\mathrm{TN}=$ total nitrogen, $\mathrm{CEC}=$ cation exchange capacity, $\mathrm{Ca}=$ calcium, $\mathrm{Mg}=$ magnesium, $\mathrm{K}=$ potassium.

\section{Conclusions}

In this study, the Veris P4000 instrument was used to acquire in-situ profile DRS spectra, $\mathrm{EC}_{\mathrm{a}}$, and $\mathrm{CI}$ simultaneously down to a $1 \mathrm{~m}$ depth. Soil core samples were obtained at the same locations for laboratory measurement of soil properties, including SOC, TN, moisture, clay, silt, sand, $\mathrm{Ca}, \mathrm{Mg}$, $\mathrm{K}, \mathrm{CEC}$, and $\mathrm{pH}$. Soil property estimates obtained using a variety of datasets, spectral preprocessing techniques, and modeling methods were compared. Conclusions from this research were:

- Of the preprocessing techniques investigated, absorbance spectra smoothed with a 30-point Gaussian window produced the most consistently accurate estimates, but only slightly better than absorbance spectra with a SNV transformation. When averaged across all soil properties, there was little difference in accuracy $\left(\Delta R^{2}=0.03\right)$ among the 10 preprocessing techniques.

- Spectra alone provided better estimates of some soil properties while the multiple sensor (DECS) dataset performed better for others. However, DECS estimates improved by more than $5 \%$ in RMSE only for $\mathrm{Ca}$, a marginal improvement with the additional complexity of multiple sensors.

- Overall, PLSR was the best modeling method, providing most accurate results for six soil properties and second best for another four, out of the 11 properties investigated. Estimation accuracy was more strongly affected by choice of modeling method than by choice of sensor dataset or preprocessing method.

- Accuracy varied considerably between two fields with similar soils, suggesting that in this case field-specific characteristics or management activities may have influenced the relationship of sensor data to soil properties.

The findings of this research regarding the best combination of sensors, preprocessing, and modeling techniques for in-situ estimation of profile soil properties should be confirmed through additional data collection and analysis for a wide range of soils and locations. Overall, this study showed that multiple soil physical and chemical properties could be estimated with good accuracy using profile spectral or DECS data with PLSR, demonstrating the ability of in-situ data collection to provide rapid assessment of soil properties at high spatial and/or temporal resolution for precision agriculture applications.

Author Contributions: K.A.S. and K.S.V. conceptualized the study, designed experiments, conducted field data and sample collection, and supervised soil processing and laboratory analyses; X.P. implemented spectral data processing and calibration modeling under the supervision of K.A.S. and M.L.; the original draft of the manuscript was written by X.P. with editorial contributions from K.A.S., K.S.V., and M.L. 
Funding: This research was funded by the Chinese National Key Research and Development Plan (2016YFD0700300-2016YFD0700304), the National Natural Science Foundation of China (31801265), the USDA Agricultural Research Service, and the China Scholarship Council.

Acknowledgments: Mention of trade names or commercial products in this publication is solely for the purpose of providing specific information and does not imply recommendation or endorsement by the U.S. Department of Agriculture or China Agricultural University. We thank Scott Drummond, Kendall Firman, Kurt Holiman, and Jill Souliere Staples for assistance with field data collection and laboratory analysis.

Conflicts of Interest: The authors declare no conflict of interest.

\section{References}

1. Stenberg, B.; Viscarra Rossel, R.A.; Mouazen, A.M.; Wetterlind, J. Visible and near-infrared spectroscopy in soil science. Adv. Agron. 2010, 107, 163-215.

2. Viscarra Rossel, R.A.; Walvoort, D.J.J.; McBratney, A.B.; Janik, L.J.; Skjemstad, J.O. Visible, near infrared, mid infrared or combined diffuse reflectance spectroscopy for simultaneous assessment of various soil properties. Geoderma 2006, 131, 59-75. [CrossRef]

3. Mouazen, A.M.; Maleki, M.R.; de Baerdemaeker, J.; Ramon, H. On-line measurement of some soil properties using a VIS-NIR sensor. Soil Tillage Res. 2007, 93, 13-27. [CrossRef]

4. Kusumo, B.H.; Hedley, C.B.; Hedley, M.J.; Hueni, A.; Tuohy, M.P.; Arnold, G.C. The use of diffuse reflectance spectroscopy for in situ carbon and nitrogen analysis of pastoral soils. Aust. J. Soil Res. 2008, 46, 623-635. [CrossRef]

5. Kweon, G.; Lund, E.; Maxton, C.; Drummond, P.; Jensen, K. In Situ Measurement of Soil Properties Using a Probe-Based VIS-NIR Spectrophotometer; Paper No. 084399; American Society of Agricultural and Biological Engineers: St. Joseph, MI, USA, 2008.

6. Chang, C.W.; Laird, D.A.; Mausbach, M.J.; Hurburgh, C.R. Near-infrared reflectance spectroscopy-principal components regression analyses of soil properties. Soil Sci. Soc. Am. J. 2001, 65, 480-490. [CrossRef]

7. Confalonieri, M.; Fornasier, F.; Ursino, A.; Boccardi, F.; Pintus, B.; Odoardi, M. The potential of near infrared reflectance spectroscopy as a tool for chemical characterization of agricultural soils. J. Near Infrared Spectrosc. 2001, 9, 123-131. [CrossRef]

8. McCarty, G.W.; Reeves, J.B., III; Reeves, V.B.; Follett, R.F.; Kimble, J.M. Mid-infrared and near-infrared diffuse reflectance spectroscopy for soil carbon measurements. Soil Sci. Soc. Am. J. 2002, 66, 640-646.

9. Lee, K.S.; Sudduth, K.A.; Drummond, S.T.; Lee, D.H.; Kitchen, N.R.; Chung, S.O. Calibration methods for soil property estimation using reflectance spectroscopy. Trans. ASABE 2010, 53, 675-684. [CrossRef]

10. Sudduth, K.A.; Hummel, J.W. Soil organic matter, CEC, and moisture sensing with a portable NIR spectrophotometer. Trans. ASAE 1993, 36, 1571-1582. [CrossRef]

11. Ben-Dor, E.; Banin, A. Near-infrared analysis as a rapid method to simultaneously evaluate several soil properties. Soil Sci. Soc. Am. J. 1995, 59, 364-372. [CrossRef]

12. Shepherd, K.D.; Walsh, M.G. Development of reflectance spectral libraries for characterization of soil properties. Soil Sci. Soc. Am. J. 2002, 66, 988-998. [CrossRef]

13. Cozzolino, D.; Moron, A. The potential of near-infrared reflectance spectroscopy to analyse soil chemical and physical characteristics. J. Agric. Sci. 2003, 140, 65-71. [CrossRef]

14. Islam, K.; Singh, B.; McBratney, A. Simultaneous estimation of several soil properties by ultra-violet, visible, and near-infrared reflectance spectroscopy. Aust. J. Soil Res. 2003, 41, 1101-1114. [CrossRef]

15. Lee, W.S.; Sanchez, J.F.; Mylavarapu, R.S.; Choe, J.S. Estimating chemical properties of Florida soils using spectral reflectance. Trans. ASAE 2003, 46, 1443-1453.

16. Baker, J.M.; Ochsner, T.E.; Venterea, R.T.; Griffis, T.J. Tillage and soil carbon sequestration-What do we really know? Agric. Ecosyst. Environ. 2007, 118, 1-5. [CrossRef]

17. Harrison, R.; Footen, P.; Strahm, B. Deep soil horizons: Contribution and importance to soil carbon pools and in assessing whole-ecosystem response to management and global change. For. Sci. 2011, 57, 67-76.

18. Dalal, R.C.; Henry, R.J. Simultaneous determination of moisture, organic carbon, and total nitrogen by near-infrared reflectance spectrophotometry. Soil Sci. Soc. Am. J. 1986, 50, 120-123. [CrossRef]

19. Hummel, J.W.; Sudduth, K.A.; Hollinger, S.E. Soil moisture and organic matter prediction of surface and subsurface soils using an NIR soil sensor. Comput. Electron. Agric. 2001, 32, 149-165. [CrossRef] 
20. Lee, K.S.; Sudduth, K.A.; Chung, S.O.; Kitchen, N.R.; Drummond, S.T. Wavelength identification and diffuse reflectance estimation for surface and profile soil properties. Trans. ASABE 2009, 52, 683-695. [CrossRef]

21. Hedley, C.; Roudier, P.; Maddi, L. VNIR soil spectroscopy for field analysis. Commun. Soil Sci. Plant Anal. 2015, 46, 104-121. [CrossRef]

22. Roudier, P.; Hedley, C.B.; Ross, C.W. Prediction of volumetric soil organic carbon from field-moist intact soil cores. Eur. J. Soil Sci. 2015, 66, 651-660. [CrossRef]

23. Hummel, J.W.; Ahmad, I.S.; Newman, S.C.; Sudduth, K.A.; Drummond, S.T. Simultaneous soil moisture and cone index measurement. Trans. ASAE 2004, 47, 607-618. [CrossRef]

24. Poggio, M.; Brown, D.J.; Bricklemyer, R.S. Comparison of Vis-NIR on in situ, intact core and dried, sieved soil to estimate clay content at field to regional scales. Eur. J. Soil Sci. 2017, 68, 434-448. [CrossRef]

25. Ackerson, J.P.; Morgan, C.L.S.; Ge, Y. Penetrometer-mounted VisNIR spectroscopy: Application of EPO-PLS to in situ VisNIR spectra. Geoderma 2017, 286, 131-138. [CrossRef]

26. Cho, Y.; Sudduth, K.A.; Drummond, S.T. Profile soil property estimation using a VIS-NIR-EC-force probe. Trans. ASABE 2017, 60, 683-692. [CrossRef]

27. Wetterlind, J.; Piikki, K.; Stenberg, B.; Söderström, M. Exploring the predictability of soil texture and organic matter content with a commercial integrated soil profiling tool. Eur. J. Soil Sci. 2015, 66, 631-638. [CrossRef]

28. Hodge, A.M.; Sudduth, K.A. Comparison of Two Spectrometers for Profile Soil Carbon Sensing; Paper No. 121338240; American Society of Agricultural and Biological Engineers: St. Joseph, MI, USA, 2012.

29. Veum, K.S.; Parker, P.A.; Sudduth, K.A.; Holan, S.H. Predicting profile soil properties with reflectance spectra via Bayesian covariate-assisted external parameter orthogonalization. Sensors 2018, 18, 3869. [CrossRef] [PubMed]

30. Nduwamungu, C.; Ziadi, N.; Tremblay, G.F.; Parent, L.-E. Near-infrared reflectance spectroscopy prediction of soil properties: Effects of sample cups and preparation. Soil Sci. Soc. Am. J. 2009, 73, 1896-1903. [CrossRef]

31. Igne, B.; Reeves, J.B., III; McCarty, G.; Hively, W.D.; Lund, E.; Hurburgh, C.R., Jr. Evaluation of spectral pretreatments, partial least squares, least squares support vector machines and locally weighted regression for quantitative spectroscopic analysis of soils. J. Near Infrared Spectrosc. 2010, 18, 167-176. [CrossRef]

32. Xu, S.; Zhao, Y.; Wang, M.; Shi, X. Comparison of multivariate methods for estimating selected soil properties from intact cores of paddy fields by Vis-NIR spectroscopy. Geoderma 2018, 310, 29-43. [CrossRef]

33. Viscarra Rossel, R.A.; Behrens, T. Using data mining to model and interpret soil diffuse reflectance spectra. Geoderma 2010, 158, 46-54. [CrossRef]

34. Minasny, B.; McBratney, A.B.; Bellon-Maurel, V.; Roger, J.M.; Gobrecht, A.; Ferrand, L.; Joalland, S. Removing the effect of soil moisture from NIR diffuse reflectance spectra for the prediction of soil organic carbon. Geoderma 2011, 118-124. [CrossRef]

35. Morgan, C.L.S.; Waiser, T.H.; Brown, D.J.; Hallmark, C.T. Simulated in situ characterization of soil organic and inorganic carbon with visible near-infrared diffuse reflectance spectroscopy. Geoderma 2009, 151, 249-256. [CrossRef]

36. Reeves, J.B. Near- versus mid-infrared diffuse reflectance spectroscopy for soil analysis emphasizing carbon and laboratory versus on-site analysis: Where are we and what needs to be done? Geoderma 2010, 158, 3-14. [CrossRef]

37. Viscarra Rossel, R.A.; Lobsey, C.R.; Sharman, C.; Flick, P.; McLachlan, G. Novel proximal sensing for monitoring soil organic C stocks and condition. Environ. Sci. Technol. 2017, 51, 5630-5641. [CrossRef] [PubMed]

38. Sudduth, K.A.; Kitchen, N.R.; Bollero, G.A.; Bullock, D.G.; Wiebold, W.J. Comparison of electromagnetic induction and direct sensing of soil electrical conductivity. Agron. J. 2003, 95, 472-482. [CrossRef]

39. McNeill, J.D. Rapid, accurate mapping of soil salinity by electromagnetic ground conductivity meters. In Advances in Measurement of Soil Physical Properties: Bringing Theory into Practice; Topp, G.C., Reynolds, W.D., Green, R.E., Eds.; SSSA: Madison, WI, USA, 1992; pp. 209-229.

40. Rhoades, J.D.; Manteghi, N.A.; Shrouse, P.J.; Alves, W.J. Soil electrical conductivity and soil salinity: New formulations and calibrations. Soil Sci. Soc. Am. J. 1989, 53, 433-439. [CrossRef]

41. ASABE Standards. Soil Cone Penetrometer; ASABE Standard S313.3; American Society of Agricultural and Biological Engineers: St. Joseph, MI, USA, 2013. 
42. ASABE Standards. Procedures for Using and Reporting Data Obtained with the Soil Cone Penetrometer; ASABE Engineering Practice EP542; American Society of Agricultural and Biological Engineers: St. Joseph, MI, USA, 2013.

43. Elbanna, E.B.; Witney, B.D. Cone penetration resistance equation as a function of the clay ratio, soil moisture content and specific weight. J. Terramech. 1987, 24, 41-56. [CrossRef]

44. Canarache, A. Factors and indices regarding excessive compactness of agricultural soils. Soil Tillage Res. 1991, 19, 145-164. [CrossRef]

45. Chung, S.O.; Sudduth, K.A.; Plouffe, C.; Kitchen, N.R. Soil bin and field tests of an on-the-go soil strength profile sensor. Trans. ASABE 2008, 51,5-18. [CrossRef]

46. Sadler, E.J.; Lerch, R.N.; Kitchen, N.R.; Anderson, S.H.; Baffaut, C.; Sudduth, K.A.; Prato, A.A.; Kremer, R.J.; Vories, E.D.; Myers, D.B.; et al. Long-term agro-ecosystem research in the Central Mississippi River Basin: Introduction, establishment, and overview. J. Environ. Qual. 2015, 44, 3-12. [CrossRef] [PubMed]

47. Nelson, D.W.; Sommers, L.E. Total carbon, organic carbon and organic matter. In Methods of Soil Analysis. Part 3-Chemical Methods; Sparks, D.L., Ed.; SSSA Book Ser. 5; SSSA: Madison, WI, USA, 1996; pp. 961-1010.

48. National Soil Survey Center. Soil Survey Laboratory Methods Manual, version 3.0; Soil Survey Investigations Report No. 42; USDA-NRCS National Soil Survey Center: Lincoln, NE, USA, 1996.

49. Wold, S.; Sjöström, M.; Eriksson, L. PLS regression: A basic tool of chemometrics. Chemom. Intell. Lab. Syst. 2001, 58, 109-130. [CrossRef]

50. Cleveland, W.S. Robust locally weighted regression and smoothing scatterplots. J. Am. Stat. Assoc. 1979, 74, 829-836. [CrossRef]

51. Cleveland, W.S.; Devlin, S.J. Locally weighted regression: An approach to regression analysis by local fitting. J. Am. Stat. Assoc. 1988, 83, 596-610. [CrossRef]

52. Barnes, R.J.; Dhanoa, M.S.; Lister, S.J. Standard normal variate transformation and de-trending of near-infrared diffuse reflectance spectra. Appl. Spectrosc. 1989, 43, 772-777. [CrossRef]

53. Beebe, K.R.; Kowalski, B.R. An introduction to multivariate calibration and analysis. Anal. Chem. 1987, 59, 1007A-1017A. [CrossRef]

54. Breiman, L.; Friedman, J.; Olshen, R.; Stone, C. Classification and Regression Trees; Wadsworth: Belmont, CA, USA, 1984.

55. Verbyla, D.L. Classification trees: A new discrimination tool. Can. J. For. Res. 1987, 17, 1150-1152. [CrossRef]

56. Clark, L.A.; Pregibon, D. Tree-based models. In Statistical Models; Chambers, J.M., Hastie, T.J., Eds.; Wadsworth: Belmont, CA, USA, 1992; pp. 377-419.

57. Therneau, T.M.; Atkinson, E.J. An Introduction to Recursive Partitioning Using the RPART Routines; Technical Report No. 61; Mayo Clinic: Rochester, MN, USA, 1997.

58. Breiman, L. Random forests. Mach. Learn. 2001, 45, 5-32. [CrossRef]

59. Brown, D.J.; Bricklemyer, R.S.; Miller, P.R. Validation requirements for diffuse reflectance soil characterization models with a case study of VNIR soil C prediction in Montana. Geoderma 2005, 129, 251-267. [CrossRef]

60. Young, F.J.; Radatz, C.A.; Marshall, C.A. Soil Survey of Boone County, Missouri; USDA-NRCS: Washington, DC, USA, 2003.

61. Yin, X.; Gupta, V.; Du, H.; Wang, X.; Miller, J.D. Surface charge and wetting characteristics of layered silicate minerals. Adv. Colloid Interface Sci. 2012, 179-182, 43-50. [CrossRef] [PubMed]

62. Levy, R.; Shainberg, I. Calcium-magnesium exchange in montmorillonite and vermiculite. Clay Clay Miner. 1972, 20, 37-46. [CrossRef]

(C) 2019 by the authors. Licensee MDPI, Basel, Switzerland. This article is an open access article distributed under the terms and conditions of the Creative Commons Attribution (CC BY) license (http:/ / creativecommons.org/licenses/by/4.0/). 